\title{
Stress Corrosion Behavior of an Aluminum-Lithium Alloy
}

\author{
Abdulbaset A. Frefer \\ Department of Mechanical and Industrial Engineering, \\ Al-Fateh University, Tripoli-Libya \\ drfrefer@hotmail.com
}

Aerospace industry now-a-days is highly interested in using high strength, light weight material system in aircraft structure.[1] lithium-containing aluminum alloys are attractive candidate materials for such structure on account of the good properties these alloys are to offer, namely, low density which eventually results in savings in weight. In addition, these alloys have high elastic modulus of elasticity, high strength, improved thermal stability, good resistance to the propagation of fatigue cracks. It was reported by some researchers that the susuceptibilty to SCC differs substantially from one aluminum alloys to another.[2-4] Although some research work on the stress corrosion cracking were done, more work is needed, especially in the aggressive environments, such as sea water with applied potential and a range of strain rate values.

The present paper focuses on the study of stress corrosion cracking (SCC) behavior of lithium containing aluminum alloy (AA8090) at the peak-aged (T851). The evaluation is based on the slow strain rate technique (SSRT) of the tested alloy in solution of 3.5\% $\mathrm{NaCl}$. The tests are conducted at room temperature using a range of strain rate values and applied potentials. The total percent elongation is determined and used to calculate the ductility ratio (\% elongation in the $\mathrm{NaCl}$ solution to $\%$ elongation in air). This ratio is used as a criterion to judge the susceptibility of the study alloy to SCC, the lower the ductility ratio, the worse the performance. The fractographic and metallographic studies are done using the optical microscopy and scanning electron microscopy.

The main objective of this study is to investigate the slow strain rate SCC behavior of the aluminumlithium alloy under study as a function of the strain rates and applied potentials used.

The CERT machine is used for SCC experiments and the electrolyte is an aqueous $\mathrm{NaCl}$ solution. Both the slow strain rate specimen dimensions and a schematic of the slow strain rate electrochemical cell set up are presented in Figures 1 and 2.

\section{References:}

1- T.H. Sanders, Jr. and E.A. Starke, Jr., Aluminum-Lithium Allotys II, Proceedings of the Second International Conference on Aluminum-Lithium Alloys, The Metallurgical Society of the AIME, New York, 1984, p.1.

2- A. Conde et al., Corrosion Science, 40 (1998) 91.

3- B. Davo et al., Corrosion Science, 48 (2006) 4113.

4- K. Mondal et al., Corrosion Engineering Science and Technology, 40 (2005) 313. 


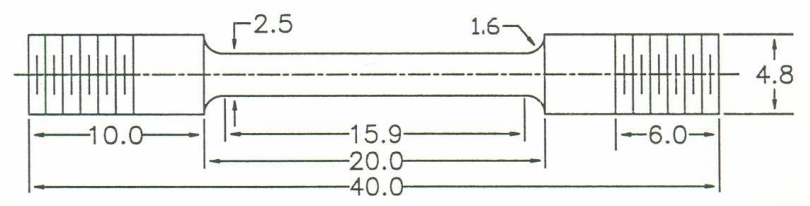

Figure 1. A schematic of the SSR specimen (in mm)

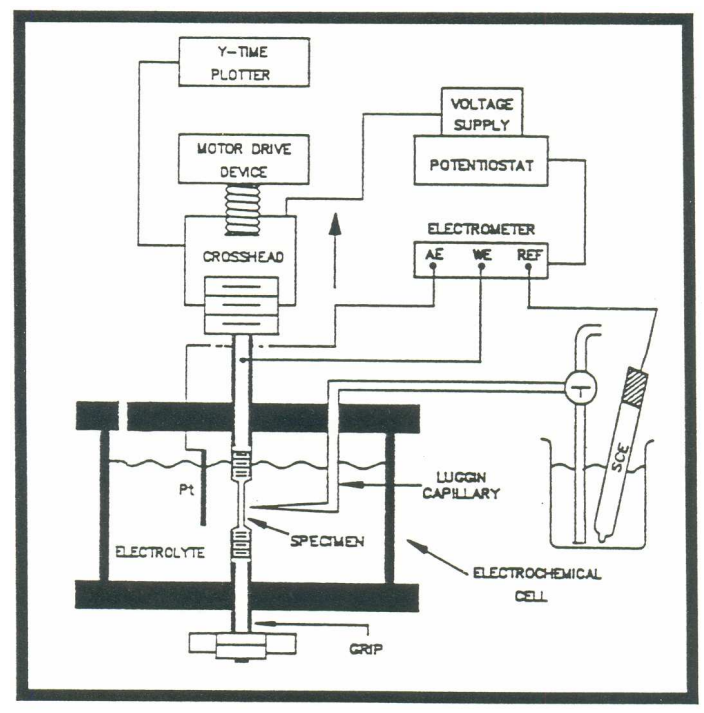

Figure 2. A schematic of the SSR electrochemical cell setup 